\title{
Porous Core-Shell Platinum-Silver Nanocatalyst for the Electrooxidation of Methanol
}

\author{
Baljit Singh,${ }^{[a, b]}$ Brian Seddon, ${ }^{[b]}$ Eithne Dempsey, ${ }^{* a, b]}$ Wynette Redington, ${ }^{[c]}$ and Calum Dickinson ${ }^{[c]}$
}

\begin{abstract}
A new class of platinum-silver nanomaterial for the catalytic electrooxidation of methanol is considered here. The material was synthesised on a carbon nanochips platform via a combination of chemical reduction to form a particulate bimetallic alloy $\left(\mathrm{Pt}_{2} \mathrm{Ag}_{1} / \mathrm{f}-\mathrm{CNC}\right)$ and an anodic-etching process to form a unique porous core-shell platinum-silver nanoparticle $\left(n p-\mathrm{Pt}_{2} \mathrm{Ag}_{1} / \mathrm{f}-\mathrm{CNC}\right)$. Morphology, structural and compositional characterisations of the alloy were performed using transmission electron microscopy (TEM), energy-dispersive X-ray spectrometry (EDX), thermogravimetric analysis (TGA) and X-ray diffraction (XRD) techniques. Data confirms average particle size of $2.07 \mathrm{~nm}$ (median $1.73 \mathrm{~nm}$ ). The alloy nature of
\end{abstract}

the nanoparticle was confirmed by XRD and TEM/EDX analysis. The $n p-\mathrm{Pt}_{2} \mathrm{Ag}_{1} / \mathrm{f}-\mathrm{CNC}$ material was examined in electrochemical studies as a catalyst for the oxidation of methanol in sulfuric acid electrolyte. Catalytic efficiency is reported in terms of oxidation current density, $134.8 \mathrm{~mA} \mathrm{mg}^{-1}$ (platinum mass) and a current ratio, $I_{\mathrm{f}} / I_{\mathrm{b}}=$ 0.86 . The electrochemical data is indicative of high catalytic rates for methanol conversion, as well as the effectiveness of porous core-shell platinum-silver particles to resist carbon monoxide poisoning. The work demonstrates improved long-term catalytic performance of a novel nanomaterial electrode offering promising energy applications.

Keywords: Fuel cell $\cdot$ Platinum-silver nanocatalyst $\cdot$ Core-shell nanoparticle $\cdot$ Methanol electrooxidation

\section{Introduction}

Direct methanol fuel cells (DMFCs) are cleaner alternative power sources for portable electronic devices and automotive propulsion systems [1,2]. However, current technical issues largely limit the extensive application of DMFCs, e.g. inferior catalytic activity in the methanol oxidation reaction and their vulnerability to anodic carbon monoxide poisoning. In addition to undesirable kinetics, cell-durability limitations, the high cost of platinum-based catalysts introduce several economic challenges. Consequently, it is important to identify and develop highly efficient yet inexpensive catalysts for methanol fuel cells.

The development of platinum nanoparticles with controlled surface morphology can provide opportunities for improvements to existing platinum catalysts $[3,4]$. PtRu based electrocatalysts are well recognised as DMFC materials due to their reliable methanol electrooxidation performance [5-7]. However, there are crucial obstacles to be overcome e.g. low activity and high cost, $\mathrm{CO}$ poisoning, and instability, for large scale commercialisation of DMFC [7-9]. In addition, the excessive use of platinum in electrode materials has also hampered the commercialisation of DMFCs. Research teams have been searching for a means to minimise or even eliminate the dependence on platinum or Pt-like precious metals.

An effective approach in this regard is to utilise alloyed or multiple-component metallic materials which is a convenient means of modifying the catalytic properties of platinum. PtRu nanowire networks [10], direct growth of single-crystal Pt nanowires on Sn@CNT nanocable [11], PtMo core-shell structures [12], PtCu alloy nanotube arrays [13], PtNi nanooctahedra [14], PtFeCo [15], and PtRuNi [16] have been examined in this regard. In tests it was reported that such alloys exhibit enhanced catalytic activity or improved carbon monoxide tolerance.

A further means is to combine platinum with a base metal, creating catalyst nanoparticles with a metal core and platinum outer surface, or shell [17]. This core-shell construction offers economic benefits - use of a low-cost metal core and a noble metal outer layer providing the same catalytic performance but at a greatly reduced cost [18]. Pure platinum deposits on non-Pt substrates were shown to display significantly modified catalytic reactivity $[18,19]$. Platinum cores modified with bimetallic alloys such as Pt/Au-shell (polymer-protected Pt@Pt/Au coreshell nanoparticles [20], using multi-step reduction of $\mathrm{HAuCl}_{4}$ and $\mathrm{H}_{2} \mathrm{PtCl}_{6}$ ) were reported. Kristian et al. [17],

[a] B. Singh, E. Dempsey

Centre for Research in Electroanalytical Technologies

(CREATE), Institute of Technology Tallaght (ITT Dublin) Tallaght, Dublin 24, Ireland.

*e-mail: Eithne.Dempsey@ittdublin.ie Baljit.Singh@ittdublin.ie

[b] B. Singh, B. Seddon, E. Dempsey MiCRA-Biodiagnostics Technology Gateway Research Centre, CASH Building-Synergy Centre, Institute of Technology Tallaght (ITT Dublin) Tallaght, Dublin 24, Ireland. *e-mail: Brian.Seddon@ittdublin.ie

[c] W. Redington, C. Dickinson Materials Surface Science Institute (MSSI), University of Limerick

Co. Limerick, Ireland. 
used a reduction strategy to synthesise a platinum shell over a gold core supported on a carbon matrix. This coreshell nanomaterial demonstrated higher specific activity as compared to conventional platinum on carbon $(\mathrm{Pt} / \mathrm{C})$ catalyst for methanol oxidation applications. Other notable examples include, $\mathrm{Ru}-\mathrm{Pt}$ core-shell nanoparticles, FePt core-shell spheres and Au@Pt/C [21-23].

Dealloying, during which an alloy is 'parted' by the selective dissolution of the electrochemically most active element(s) [24], has recently attracted considerable attention for the fabrication of a class of nanoporous metals and alloys for fuel cell utility. This process relies on the less noble metal (lower standard electrode potential) experiencing greater corrosive dissolution than the more noble metal in the alloy, leading to the formation of a material with a bi-continuous metal-and-void structure. Multiple-component porous alloys with $\mathrm{Cu}, \mathrm{Pd}, \mathrm{Ag}$ etc. [2527] and binary alloys such as PdNi [28] and PtAu [29] have been synthesised successfully using a dealloying approach. These materials feature large specific surface areas which greatly improve catalytic activity and performance.

This work focuses on a platinum-silver nanomaterial synthesised using chemical reduction on a stable carbon nanochips support. The alloyed material undergoes anodic etching (surface dealloying) to generate a porous nanoparticle with a core-shell structure. The surface of the particle is composed of platinum atoms pitted with voids following the expulsion of silver atoms of the original alloy. The core of the structure retains the platinumsilver composition. This new nanomaterial was studied for its efficiency towards methanol electrooxidation and has demonstrated effective platinum utilisation relative to conventional platinum catalysts.

\section{Experimental}

\subsection{Materials}

Silver nitrate was purchased from Johnson Matthey Chemicals (Precious Metal Division, Enfield, UK). Hydrogen hexahydroxyplatinate(IV) $\left(\mathrm{H}_{2} \mathrm{Pt}(\mathrm{OH})_{6}\right)$, potassium hydroxide, isopropyl alcohol, ethylene glycol, trisodium citrate, nitric acid, sulfuric acid and methanol (anhydrous, $99.8 \%$ ) were purchased from Sigma Aldrich. Carbon nanochips (CNCs, HT3000, 99.99\% carbon) were purchased from Catalytic Materials LLC. Ultrapure water purified with purelab option water equipment (ELGA co. Ltd.) was exclusively used in all experiments.

\subsection{Carbon Nanochips}

Carbon nanochips are an interesting class of graphite nanofibers introduced by Baker et al. [30]. The material is processed under an inert gas environment at temperatures up to $3000^{\circ} \mathrm{C}$, which forms flattened chip-shaped structures, ideal for the functionalisation and anchoring of catalyst nanoparticles onto the surface of the support.
CNCs are treated with acid solution prior to deposition of nanoparticles; $300 \mathrm{mg}$ CNCs were sonicated for $2 \mathrm{~h}$ in $\mathrm{H}_{2} \mathrm{SO}_{4} / \mathrm{HNO}_{3}$ acid solution $(3: 1,125 \mathrm{~mL}$ acid solution diluted to $250 \mathrm{~mL}$ with de-ionised water), followed by further dilution (total volume $500 \mathrm{~mL}$ ) before being kept overnight at room temperature. Subsequently, the reaction mixture was filtered and washed with excess of distilled water followed by acetone and isopropyl alcohol washing in order to remove residual catalyst and impurities. The sonication was repeated once more in concentrated acid mixture $\left(\mathrm{H}_{2} \mathrm{SO}_{4} / \mathrm{HNO}_{3}, 3: 1\right)$ for $2 \mathrm{~h}$ followed by dilution of the acid mixture with de-ionised water, filtering and washing with excess de-ionised water (to neutral $\mathrm{pH}$ ). The material was finally dried under vacuum at $90^{\circ} \mathrm{C}$ and the functionalised carbon nanochips obtained labelled as f-CNC throughout text.

\subsection{Synthesis of $\mathrm{Pt}_{2} \mathrm{Ag}_{1} / \mathrm{f}-\mathrm{CNC}$}

Preparation of $\mathrm{Pt}_{2} \mathrm{Ag}_{1} / \mathrm{f}-\mathrm{CNC}$ (total metal loading 20 wt \%) involved; $80 \mathrm{mg}$ of functionalised carbon nanochips being well dispersed in a solvent mixture (ethylene glycol and water, $3: 2,90 \mathrm{ml}$ ) via sonication ( $\sim 70$ minutes). This was followed by dropwise addition of $\mathrm{Pt}$ and $\mathrm{Ag}$ precursor solutions $\left(\mathrm{H}_{2} \mathrm{Pt}(\mathrm{OH})_{6}, 20.45 \mathrm{mg}\right.$ and $\left.\mathrm{AgNO}_{3}, 10.5 \mathrm{mg}\right)$ in ethylene glycol/water $(3: 2,180 \mathrm{ml})$ at the maintained rate over a period of $5 \mathrm{~h}$ with continuous stirring. Sodium citrate $(90 \mathrm{mg})$ was dissolved in the same solvent mixture and added to the reaction mixture. The solution was sonicated, stirred and then the $\mathrm{pH}$ was maintained at 8.0 by the addition of $\mathrm{KOH}$ solution (in the same solvent mixture, $\left.\mathrm{EG} / \mathrm{H}_{2} \mathrm{O}, 3: 2\right)$. The solution was sonicated (10 min) and stirred well before being refluxed at $135^{\circ} \mathrm{C}$ for $8 \mathrm{~h}$ to ensure complete reduction of $\mathrm{Pt}$ and $\mathrm{Ag}$ ions. The reaction mixture was cooled with continuous stirring and filtered using Millipore filter paper $(0.45 \mu \mathrm{m})$ followed by repeatedly washing with deionised water and dried under vacuum at $60^{\circ} \mathrm{C}$ for $12 \mathrm{~h}$. The so-obtained nanocatalyst was labelled as $\mathrm{Pt}_{2} \mathrm{Ag}_{1} / \mathrm{f}-\mathrm{CNC}$. Following electrochemical etching treatment (see Section 3.2), the catalyst was labelled as $n p-\mathrm{Pt}_{2} \mathrm{Ag}_{1} / \mathrm{f}-\mathrm{CNC}$.

\subsection{Instrumentation}

The X-ray diffraction (XRD) pattern of the materials was obtained using a Rigaku D/MAX-PC 2500 X-ray diffractometer with a $\operatorname{CuK} \alpha\left(\theta=1.54 \mathrm{~A}^{\circ}\right)$ radiation source operating at $40 \mathrm{kV}$ and $200 \mathrm{~mA}$. Surface morphology examination and particle distribution analysis of the nanoparticles was performed using transmission electron microscopy (TEM) with a JEOL 2011 operated at $200 \mathrm{kV}$ using a $\mathrm{LaB}_{6}$ filament equipped with a Gatan Multiscan Camera 794 and the DF-STEM with a JEOL 2100F operated at $200 \mathrm{kV}$ using a field emission electron source equipped with a Gatan Ultrascan Camera. The identity of each element was confirmed by EDX. Thermogravimetric analysis was performed using a Thermal Advantage Q50 
Table 1. Current density data relating to the electrooxidation of methanol at $n p-\mathrm{Pt}_{2} \mathrm{Ag}_{1} / \mathrm{f}-\mathrm{CNC}$ and $\mathrm{Pt}_{1} \mathrm{Ag}_{1} @ \mathrm{Pt}_{1} / \mathrm{f}-\mathrm{CNC}$ nanomaterial electrodes. $L_{\mathrm{Pt}}$ : platinum loading $(\mathrm{Pt}, \mu \mathrm{g}) ; I_{\mathrm{f}}$ : forward anodic peak current; $j$ : current density (forward peak, $\mathrm{mA} \mathrm{mg}^{-1}{ }_{\mathrm{Pt}}$ ); $I_{\mathrm{decrease}}$ : decrease in current response between $1^{\text {st }}$ and $30^{\text {th }}$ cycle.

\begin{tabular}{llcccc}
\hline Material & $L_{\mathrm{Pt}}(\mu \mathrm{g})$ & Cycle No. & $I_{\mathrm{f}}(\mu \mathrm{A})$ & $j\left(\mathrm{mAmg}^{-1} \mathrm{pt}\right)$ & $I_{\text {decrease }}(\%)$ \\
\hline$n p-\mathrm{Pt}_{2} \mathrm{Ag}_{1} / \mathrm{f}-\mathrm{CNC}$ & 11.78 & $1 \mathrm{st}$ & 1588 & 134.8 & 3.6 \\
$\mathrm{Pt}_{1} \mathrm{Ag}_{1} @ \mathrm{Pt}_{1} / \mathrm{f}-\mathrm{CNC}$ & 12.74 & $30 \mathrm{th}$ & 1530 & 129.9 & 37.6 \\
& & $1 \mathrm{st}$ & 1244 & 64.8 & 33.6
\end{tabular}

with a platinum pan, balance $\mathrm{N}_{2}$ flow $40 \mathrm{mLmin}^{-1}$ and sample $\mathrm{N}_{2}$ flow $60 \mathrm{~mL} \mathrm{~min}^{-1}$.

\subsection{Electrochemistry}

\subsubsection{Electrode Preparation}

Prior to electrochemical measurements, a glassy carbon electrode (GCE) was polished with 1.0, 0.3, 0.05 micron size alumina powders, sonicated in acetone and de-ionised water, washed with deionised water and dried at room temperature. The platinum-silver/f-CNC materials were immobilised $(20 \mu \mathrm{L})$ onto a clean glassy carbon electrode by drop casting. Typical suspensions of the synthesised materials were prepared by suspending catalysts in water isopropyl alcohol mixture $(3: 1)$. $20 \mu \mathrm{L}$ of $1 \%$ Nafion solution (diluted from $5 \%$ Nafion solution) was then added to the mixture $(1 \mathrm{~mL})$ which was sonicated for $20 \mathrm{~min}$ in order to achieve a uniform dispersion of particles. The suspension (Pt loading was calculated using TGA wt (\%), Table 1) was then transferred to the electrode surface using a micropipette to form a thin film on the surface of the electrode-packed CNC layer of several hundred micron thicknesses.

\subsubsection{Electrochemical Characterisation}

Cyclic voltammetry studies were carried out using an electrochemical workstation $\mathrm{CH}$ Instruments Inc. 660C. In acidic electrolyte $\left(\mathrm{H}_{2} \mathrm{SO}_{4}\right)$, using a conventional threeelectrode cell at room temperature. A glassy carbon electrode modified with synthesised catalyst served as the working electrode, while a platinum wire and a standard $\mathrm{Ag} / \mathrm{AgCl}$ electrode were used as the counter and reference electrodes respectively. The de-alloying procedure was performed in $0.5 \mathrm{M} \mathrm{H}_{2} \mathrm{SO}_{4}(5 \mathrm{~mL})$ using cyclic voltammetry (30 cycles, potential window $-0.2 \mathrm{~V}-1.2 \mathrm{~V})$. The electrochemical characterisation of nanomaterial modified electrodes was then repeated in $0.5 \mathrm{M} \mathrm{H}_{2} \mathrm{SO}_{4}$.

\subsubsection{Methanol Electrooxidation}

Methanol electrooxidation studies were performed in sulfuric acid electrolyte. The electrochemical responses for the catalyst modified glassy carbon electrodes before and after the electrochemical treatment, were recorded towards methanol electrooxidation $\left(1 \mathrm{M} \mathrm{CH} \mathrm{CH}_{3} \mathrm{OH}+0.5 \mathrm{M}\right.$ $\left.\mathrm{H}_{2} \mathrm{SO}_{4}, 5 \mathrm{ml}\right)$ using cyclic voltammetry; potential window $(0.0 \mathrm{~V}-1.0 \mathrm{~V})$, at scan rate $0.05 \mathrm{~V} / \mathrm{s}$ vs. $\mathrm{Ag} / \mathrm{AgCl}$.

\section{Results and Discussion}

\subsection{Structural and Compositional Analysis}

In order to obtain information on the nature and structural features of $\mathrm{Pt}_{2} \mathrm{Ag}_{1} / \mathrm{f}-\mathrm{CNC}$, XRD analysis was performed with results shown in Figure 1. Nanomaterial showed diffraction peaks that could be indexed to $\left(\begin{array}{lll}1 & 1 & 1\end{array}\right)$, (2 00 0), (2 20 ) , ( $\left.\begin{array}{lll}3 & 1 & 1\end{array}\right)$ and (2 22 ). A sharp peak centered at approx. $26.7^{\circ}$ along with peak at $54.8^{\circ}$ corresponding to carbon (carbon nanochips) was observed in $\mathrm{Pt}_{2} \mathrm{Ag}_{1} / \mathrm{f}-$ $\mathrm{CNC}$. Figure $1 \mathrm{~b}$ shows an extended view of XRD pattern $\left(35-50^{\circ}\right)$ along with the Ag (reference code: 01-087-0719)
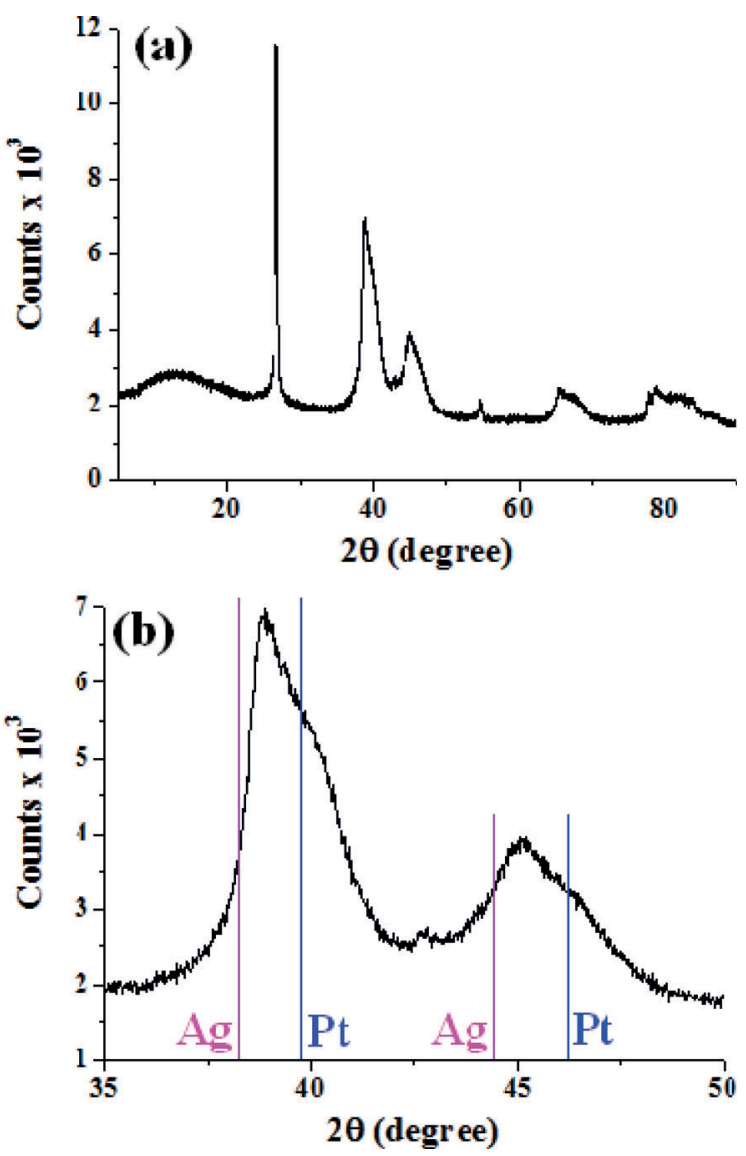

Fig. 1. (a) XRD pattern for $\mathrm{Pt}_{2} \mathrm{Ag}_{1} / \mathrm{f}-\mathrm{CNC}$. (b) Extended view of XRD pattern along with the $\mathrm{Ag}$ (reference code: 01-087-0719) and Pt (reference code: 00-004-0802) reference (crystal system: cubic, space group: Fm-3m, space group number: 225) lines, labelled as Ag and Pt. 

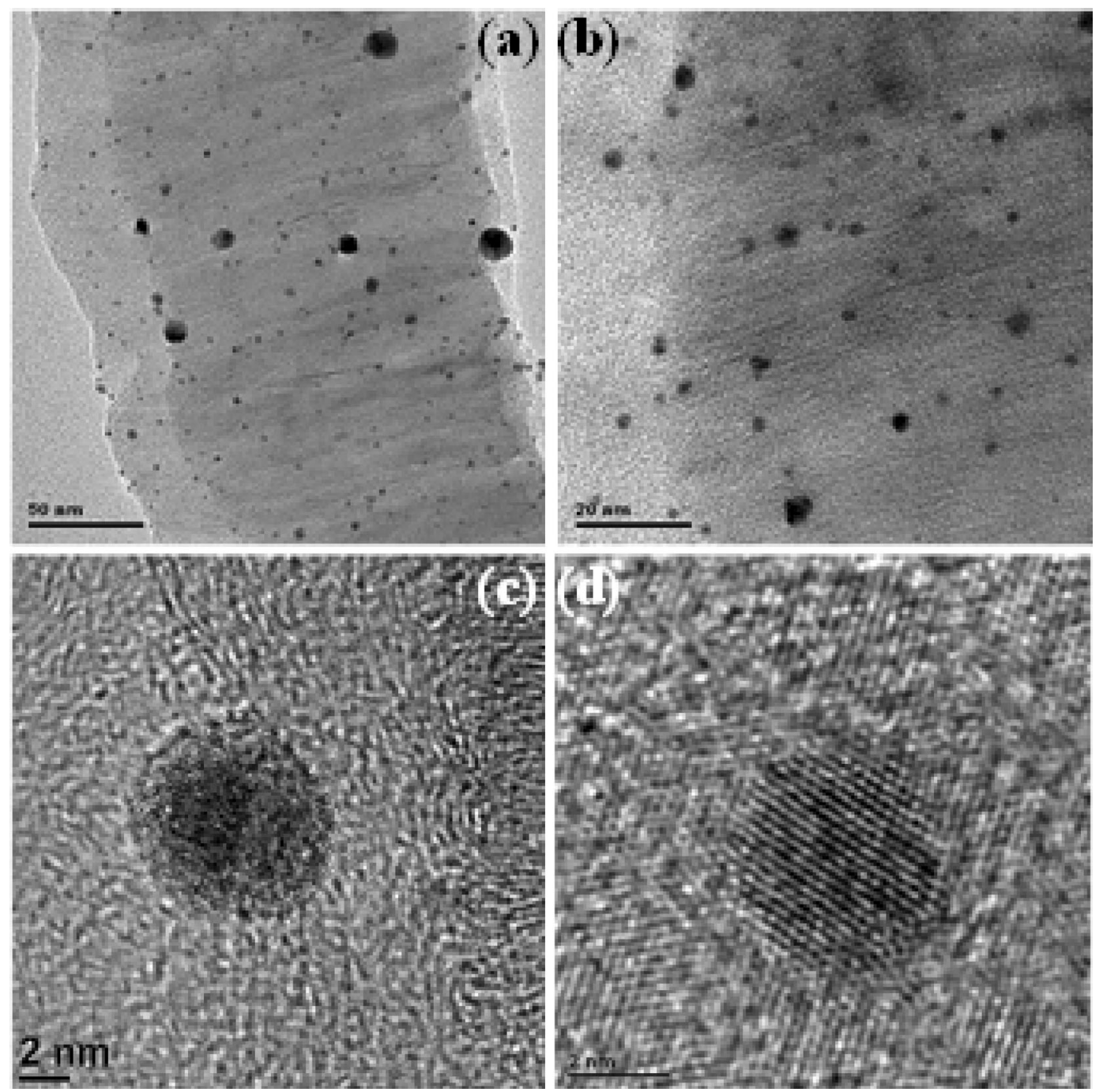

Fig. 2. Transmission electron micrographs for $\mathrm{Pt}_{2} \mathrm{Ag}_{1} / \mathrm{f}-\mathrm{CNC}$. Scale bar: Image (a) $50 \mathrm{~nm}$, (b) $20 \mathrm{~nm}$ and (c and d) $2 \mathrm{~nm}$.

and Pt (reference code: 00-004-0802) reference lines labelled as $\mathrm{Ag}$ and Pt. The observed diffraction peaks for $\mathrm{Pt}_{2} \mathrm{Ag}_{1} / \mathrm{f}-\mathrm{CNC}$ are located between $\mathrm{Pt}$ and $\mathrm{Ag}$ positions providing confirmation of the alloy character of the material. Peak broadening can be attributed to the small crystallite size for $\mathrm{Pt}_{2} \mathrm{Ag}_{1} / \mathrm{f}-\mathrm{CNC}$. Overall, XRD peak positions reveal that $\mathrm{Pt}_{2} \mathrm{Ag}_{1} / \mathrm{f}-\mathrm{CNC}$ has alloy characteristics further supported by TEM/EDX studies.

Figure 2 shows the transmission electron micrographs for $\mathrm{Pt}_{2} \mathrm{Ag}_{1} / \mathrm{f}-\mathrm{CNC}$, confirming the particle size and nanoparticle decoration onto the carbon nanochips. The particle size distribution (Figure 3 ) was created by measuring 516 particles from randomly chosen areas during TEM measurements. The evaluation of the characteristic diameter of the PtAg based nanoparticles arising from analysis of the high-resolution images (HRTEM) over randomly chosen areas resulted in a narrow size distribution of particles. Average particle size for $\mathrm{Pt}_{2} \mathrm{Ag}_{1} / \mathrm{f}-\mathrm{CNC}$ was found to be $2.07 \mathrm{~nm}$, with standard deviation $(1.52 \mathrm{~nm})$, median $(1.73 \mathrm{~nm})$, mode $(1.53 \mathrm{~nm})$, maximum size $(14.71 \mathrm{~nm})$ and minimum size $(0.45 \mathrm{~nm})$ respectively. The high standard deviation is due to the presence of small amount (1-2\% by count) of the larger sized particles $(\sim 10 \mathrm{~nm})$. Very few particles of $>4 \mathrm{~nm}(4-14 \mathrm{~nm})$ were found in the TEM

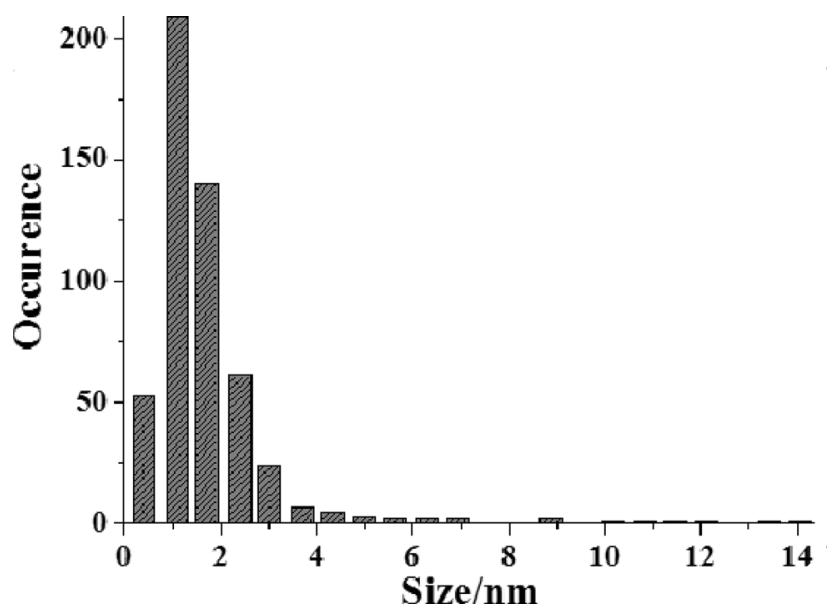

Fig. 3. Particle size distribution from TEM analysis for $\mathrm{Pt}_{2} \mathrm{Ag}_{1} /$ f-CNC. 

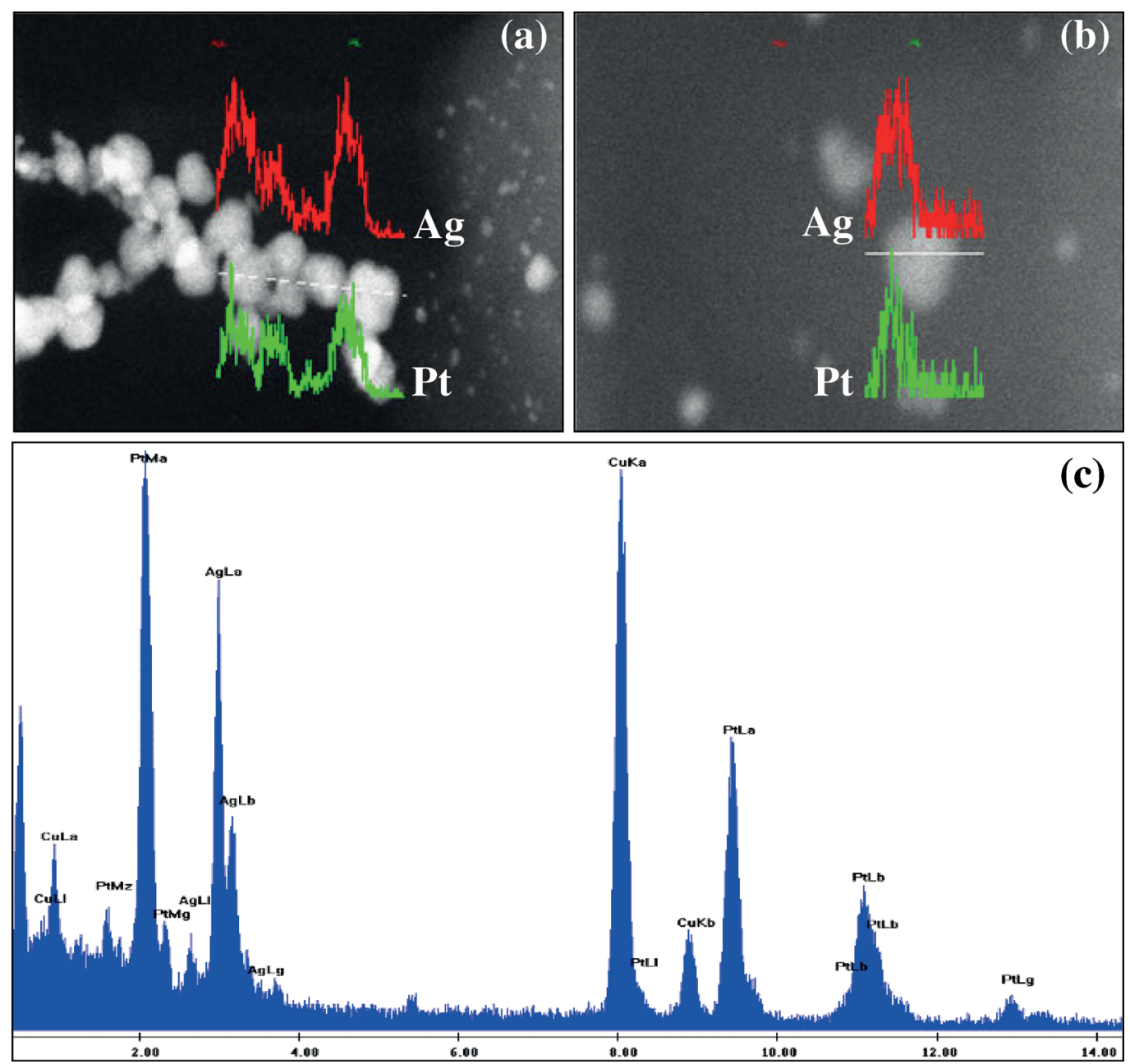

Fig. 4. TEM/EDS analysis (a) cluster of nanoparticles and (b) single particle in the $\mathrm{Pt}_{2} \mathrm{Ag}_{1} / \mathrm{f}-\mathrm{CNC}$ sample, confirming the presence of both (Pt and $\mathrm{Ag}$ ) and alloy structure for $\mathrm{Pt}_{2} \mathrm{Ag}_{1} / \mathrm{f}-\mathrm{CNC}$. (c) EDX profiles showing presence of $\mathrm{Pt}$ and $\mathrm{Ag}$ in $\mathrm{Pt}_{2} \mathrm{Ag}_{1} / \mathrm{f}-\mathrm{CNC}$.

analysis. The nanoparticle dispersion and decoration was also confirmed using dark field TEM data (data not shown). From the HRTEM images, it can be seen that the nanoparticles appear to be entirely crystalline (in agreement with XRD studies), as evidenced by the lattice fringes.

TEM-EDX analysis further confirms the identity and presence of $\mathrm{Pt}$ and $\mathrm{Ag}$ in $\mathrm{Pt}_{2} \mathrm{Ag}_{1} / \mathrm{f}-\mathrm{CNC}$. Figure 4 shows TEM analysis/profiles for (a) cluster of nanoparticles and (b) a single particle in the $\mathrm{Pt}_{2} \mathrm{Ag}_{1} / \mathrm{f}-\mathrm{CNC}$ sample, confirming the metallic content in both the cases. All individual particle and cluster profiles measured indicated the presence of both metals ( $\mathrm{Pt}$ and $\mathrm{Ag}$ ), providing further confirmation of the alloyed structure of $\mathrm{Pt}_{2} \mathrm{Ag}_{1} / \mathrm{f}-\mathrm{CNC}$. The EDX profile for $\mathrm{Pt}_{2} \mathrm{Ag}_{1} / \mathrm{f}-\mathrm{CNC}$ is shown in Figure $4 \mathrm{c}$.

In order to confirm total metallic content, thermogravimetric analysis for $\mathrm{Pt}_{2} \mathrm{Ag}_{1} / \mathrm{f}-\mathrm{CNC}$ was carried out over the temperature range $20-800^{\circ} \mathrm{C}$ at a temperature ramp of $20^{\circ} \mathrm{C} / \mathrm{min}$. The slight initial weight loss up to $450^{\circ} \mathrm{C}$ was due to the loss of residual water and slow carbon oxidation followed by rapid weight loss attributed to fast carbon degradation/oxidation. The major weight loss oc- cured around $600-650{ }^{\circ} \mathrm{C}-$ due to the ready oxidation of support material in the presence of $\mathrm{O}_{2}$ (temperature ramp $20^{\circ} \mathrm{C} / \mathrm{min}$ from $600^{\circ} \mathrm{C}-800^{\circ} \mathrm{C}$ is in the presence of oxygen). A stable profile was observed subsequently and the residue metallic content for $\mathrm{Pt}_{2} \mathrm{Ag}_{1} / \mathrm{f}-\mathrm{CNC}$ was quantified at $22.1 \%$. The metallic weight (wt \%) obtained from TGA analysis is in good agreement with the theoretical metal loading $(20 \%)$ and supports the synthetic composition.

\subsection{Nanomaterial Electrochemistry}

The electrochemical characteristics of the platinum-sliver alloy were examined by cyclic voltammetry in a sulfuric acid electrolyte. During continuous-scan experiments over the potential range of $-0.2 \mathrm{~V}$ to $+1.2 \mathrm{~V}$, the material gave rise to redox behaviour which is typical of the platinum-silver composition of the electrode - see Figure 5. Voltammetric waves for hydrogen adsorption and desorption at a platinum surface dominate the profile at ca. $0.0 \mathrm{~V}$ to $-0.2 \mathrm{~V}$. Platinum metal oxidation is prevalent in the voltammetry beyond $+1.0 \mathrm{~V}$ with a well defined sur- 


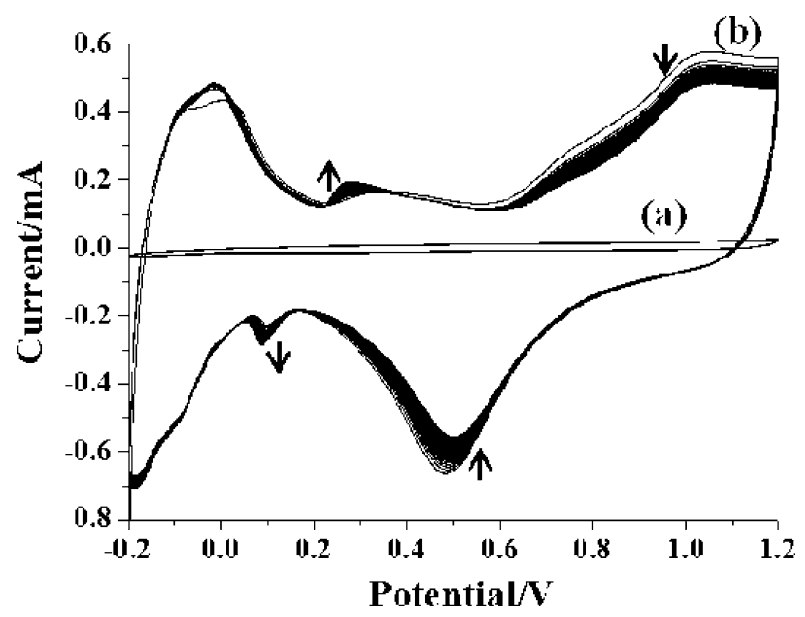

Fig. 5. Cyclic voltammetry (a) CNC modified glassy carbon electrode and (b) for the nanomaterial electrode following anodic etching $\left(n p-\mathrm{Pt}_{2} \mathrm{Ag}_{1} / \mathrm{f}-\mathrm{CNC}\right.$ modified glassy carbon electrode) in sulfuric acid solution; Electrolyte: $\mathrm{H}_{2} \mathrm{SO}_{4} 0.5 \mathrm{M}$. Electrode potentials vs. $\mathrm{Ag} / \mathrm{AgCl}$, with a scan rate $0.1 \mathrm{~V} / \mathrm{s}$ (30 cycles).

face oxide reduction peak occurring at around $+0.5 \mathrm{~V}$ (first scan data). The voltammetry also reveals silver redox electrochemistry at $+0.3 \mathrm{~V}$ for metallic silver oxidation and a sharp peak corresponding a cathodic process at $+0.1 \mathrm{~V}$ vs. $\mathrm{Ag} / \mathrm{AgCl}$.

A striking event which became apparent during voltammetry experiments was that of an electrochemicallydriven etching process. This involved the formation of a white precipitate of silver sulfate which effuses from the electrode surface during the anodic cycle. A cascade of insoluble material was observed initially in the electrochemical cell, subsiding upon repeat scanning with no further precipitate crystals being visible.

The electrochemical properties of this platinum-silver alloy are modified over the measurement period (Figure 5). The voltammetry reveals a gradual decrease in the platinum waves owing to mass transport depletion effects in the CNC packed layer. Hydrogen voltammetric features remain largely unperturbed. This is consistent with a stable platinum surface within the nanomaterial. Extended scanning experiments identified the removal of the surface silver from the alloyed structure. It was also noted that even after prolonged and continuous scanning, silver electrochemistry remained a characteristic of the overall voltammetric profile. As the anodic etching process evolves, more of the silver in the nanoparticle core becomes exposed to the acidic electrolyte and is therefore available for electrochemical oxidation. Accessible surface atoms undergo silver-ion formation by electrooxidation, followed by crystal formation with electrolyte sulfate ions. Much of this insoluble silver leaves the electrode as an electrolyte precipitate, while a portion deposits onto other parts of the nanoparticle surface. Furthermore, silver aquo-ions created deeper within the CNC packed layer can be redeposited onto the carbon nanochips support during the return cathodic scan. Each of these chem-

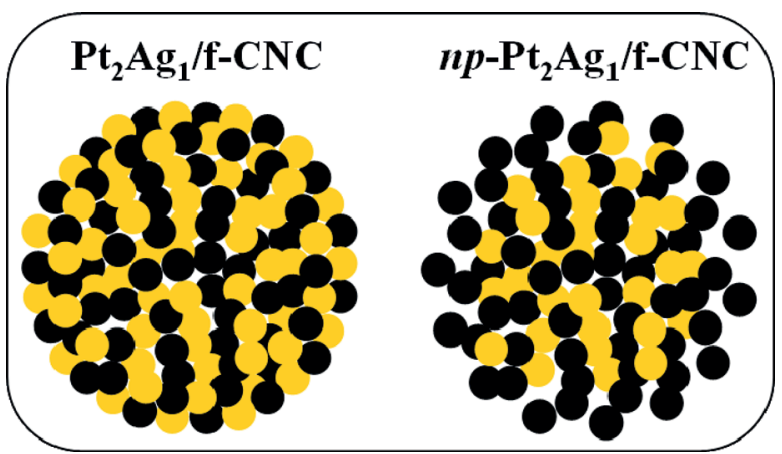

Fig. 6. Graphical representation for $\mathrm{Pt}_{2} \mathrm{Ag}_{1} / \mathrm{f}-\mathrm{CNC}$ (before electro-etching treatment) and porous core-shell platinum-silver nanomaterial ( $n p-\mathrm{Pt}_{2} \mathrm{Ag}_{1} / \mathrm{f}-\mathrm{CNC}$, after electro-etching treatment). $\mathrm{Pt}$ and $\mathrm{Ag}$ are indicated by black and yellow spheres respectively; CNC not shown.

ical and mass transport processes at the electrode interface augment the silver electrochemistry observed for this nanomaterial.

The expulsion of silver atoms from the platinum-silver nanoparticle $\left(\mathrm{Pt}_{2} \mathrm{Ag}_{1} / \mathrm{f}-\mathrm{CNC}\right)$ by anodic etching gives rise to the prospect of electrogenerating a modified alloy particle with high surface porosity and potentially novel catalytic properties. In this case, the new particle would retain the original structural features of the platinum-silver alloy at the particle centre with surface voids where silver atoms were displaced. The material would therefore assume a porous core-shell nanoparticle form, with an outer surface of platinum atoms (see schematic Figure 6). The core of this particle is structurally and electronically identical to the original platinum-silver alloy. This new particle, supported on CNC support is designated by $n p$ $\mathrm{Pt}_{2} \mathrm{Ag}_{1} / \mathrm{f}-\mathrm{CNC}$. A feature which is apparent in the electrochemistry of porous core-shell platinum-silver nanoparticles $\left(n p-\mathrm{Pt}_{2} \mathrm{Ag}_{1} / \mathrm{f}-\mathrm{CNC}\right)$ is the potential for core atoms to be exposed to electrolyte. This electronically alters the nature of the nanoparticle and hence its catalytic function.

\subsection{Methanol Electrooxidation}

\subsubsection{Performance of $\mathrm{Pt}_{2} A g_{1} / f-C N C$ and $n p-P t_{2} A g_{1} / f-C N C$ Nanomaterials}

Interest here lies in the application of porous core-shell platinum-silver nanoparticles for methanol oxidation and their potential use in efficient methanol fuel cells. The electrooxidation of methanol in sulfuric acid electrolyte at platinum-silver nanoparticle materials was examined for non-etched and etched materials. Figure 7 shows the electrochemistry of methanol at the original platinumsilver nanomaterial $\left(\mathrm{Pt}_{2} \mathrm{Ag}_{1} / \mathrm{f}-\mathrm{CNC}\right)$ which has not yet undergone an anodic etching process to eliminate silver from the nanoparticle. Platinum metal oxidation is defined beyond $+0.8 \mathrm{~V}$, with no apparent oxide reduction observed in the return cathodic scan. Silver electrochemistry commences in successive scans and becomes an es- 


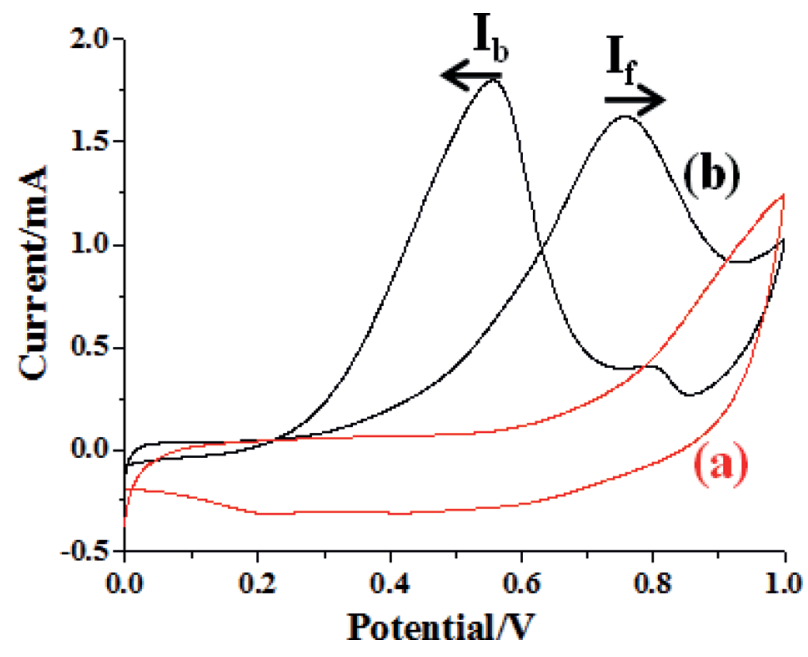

Fig. 7. Cyclic voltammetry of methanol in sulfuric acid solution at platinum-silver nanomaterials: (a) $\mathrm{Pt}_{2} \mathrm{Ag}_{1} / \mathrm{f}-\mathrm{CNC}$ and (b) $n p$ $\mathrm{Pt}_{2} \mathrm{Ag}_{1} / \mathrm{f}-\mathrm{CNC}$ modified glassy carbon electrode. Electrolyte: $\mathrm{H}_{2} \mathrm{SO}_{4} 0.5 \mathrm{M}$. Electrode potentials vs. $\mathrm{Ag} / \mathrm{AgCl}$, with a scan rate $0.05 \mathrm{~V} / \mathrm{s}$ (first scan).

tablished characteristic with silver oxidation at $+0.25 \mathrm{~V}$ and reduction at $+0.05 \mathrm{~V}$ vs. $\mathrm{Ag} / \mathrm{AgCl}$. This material shows no sign of electrooxidative catalysis for methanol over the next successive thirty scans.

The anodic etching employed to generate a porous particle structure is a dealloying process which eliminates silver atoms from the particle surface as a crystalline sulfate deposit. This substance precipitates into the electrolyte as well as onto the supporting nanomaterial. In sulfuric acid this insoluble silver salt is effectively eliminated from the nanomaterial, however, in the presence of methanol, precipitate poisoning of platinum surfaces becomes evident. This ultimately limits the accessibility of methanol molecules to the platinum and therefore its use as a catalyst. It should be noted that methanol electrooxidation was observed with $P t_{2} A g_{1} / f-C N C$ materials. It was found that upon removal of the nanomaterial electrode from the electrochemical cell, washing with deionised water and repeat anodic scanning in methanolic sulfuric acid ( $>60$ scans), the platinum-silver alloy displayed methanol oxidation characteristics. The catalytic performance of this in situ anodically etched platinum-silver material to methanol oxidation is limited however by silver-salt poisoning.

Studies with the nanomaterial alloy which had formerly been electro-etched highlight the advantages of a porous core-shell nanocatalyst for methanol electrooxidation. In cyclic voltammetry two peaks were observed, one in the forward scan, $I_{\mathrm{f}}$ attributed to the electrooxidation of methanol and one in the reverse scan, $I_{\mathrm{b}}$. The latter is related to the electrochemistry of methanol oxidation products such as carbon monoxide. An important parameter in evaluating methanol electrocatalysts is their tolerance to electrode poisoning by species formed during the primary oxidation reaction. The extent of poisoning is defined by the magnitude of the forward anodic peak cur- rent, $I_{\mathrm{f}}$ to the reverse peak current, $I_{\mathrm{b}}$ [31-33]. A higher value of the current ratio, $I_{\mathrm{f}} / I_{\mathrm{b}}$ implies a relatively complete methanol electrooxidation, involving production of $\mathrm{CO}_{2}$, and reflects the fraction of the catalyst surface that is not poisoned by $\mathrm{CO}$ adsorption. Values of $I_{\mathrm{f}}$ and $I_{\mathrm{b}}$ are therefore useful measures of a catalyst's tolerance to poisoning and are important in the evaluation of a material's catalytic performance. $I_{\mathrm{f}} / I_{\mathrm{b}}$ values and the methanol oxidation current density, defined by the unit mass of platinum, $I_{\mathrm{f}} / \mathrm{m}$ were determined in the case of $\mathrm{Pt}_{2} \mathrm{Ag}_{1} / \mathrm{f}-\mathrm{CNC}$ and $n p-\mathrm{Pt}_{2} \mathrm{Ag}_{1} / \mathrm{f}-\mathrm{CNC}$ materials. For the electro-etched particle, the current ratio was measured $c a$. 0.86 on the first scan, while $I_{\mathrm{f}} / I_{\mathrm{b}}$ values for the in situ material were non-defined in the first scan, increasing to $>0.80$ after 69 scans; i.e. anodic etching can be achieved in the methanol-acid electrolyte. Methanol oxidation current densities calculated per mg mass of platinum have economic implications in catalyst design. In the present study the electro-etched nanomaterial $\left(n p-\mathrm{Pt}_{2} \mathrm{Ag}_{1} / \mathrm{f}-\mathrm{CNC}\right)$ prepared in sulfuric acid electrolyte was compared with the in situ processed catalyst for methanol electrooxidation. The highest current density, $I_{\mathrm{f}} / m$, achieved for the in situ catalyst in our work was no more than $22 \mathrm{~mA} \mathrm{mg}^{-1}$ for methanol electrooxidation. $I_{\mathrm{f}} / m$ measures for the $n p-\mathrm{Pt}_{2} \mathrm{Ag}_{1} / \mathrm{f}-$ $\mathrm{CNC}$ nanomaterial was predominantly $>130 \mathrm{~mA} \mathrm{mg}^{-1}$ (Pt). The differences observed between the $\mathrm{Pt}_{2} \mathrm{Ag}_{1} / \mathrm{f}-\mathrm{CNC}$ and $n p-\mathrm{Pt}_{2} \mathrm{Ag}_{1} / \mathrm{f}-\mathrm{CNC}$ materials may to a great part be attributable to catalytic poisoning of platinum surface by silver salt precipitation.

\subsubsection{Performance of $n p-P t_{2} A g_{1} / f-C N C$ and $P t_{1} A g_{1} @ P t_{1} / f$ - CNC Nanomaterials}

Methanol electrooxidation characteristics of the porous core-shell platinum-silver nanomaterial $\left(n p-\mathrm{Pt}_{2} \mathrm{Ag}_{1} / \mathrm{f}-\right.$ $\mathrm{CNC}$ ) and a core-shell platinum-silver nanomaterial synthesised by chemical reduction onto a CNC platform $\left(\mathrm{Pt}_{1} \mathrm{Ag}_{1} @ \mathrm{Pt}_{1} / \mathrm{f}-\mathrm{CNC}\right)$ were compared (illustrated in Figure 8). This core-shell particle was formed by the same chemical method (described in a Note after Conclusions (Section 4$)$ as the alloy $\left(\mathrm{Pt}_{2} \mathrm{Ag}_{1} / \mathrm{f}-\mathrm{CNC}\right)$, and is employed here for comparative purposes. $\mathrm{Pt}_{1} \mathrm{Ag}_{1} @ \mathrm{Pt}_{1} / \mathrm{f}-\mathrm{CNC}$ has a similar particle-size profile to that of the original alloy particle, with a platinum-silver alloy core and platinum shell.

The electrochemical catalysis of the porous core-shell nanoparticle, $n p-\mathrm{Pt}_{2} \mathrm{Ag}_{1} / \mathrm{f}-\mathrm{CNC}$ towards methanol oxidation impressively out-performed the platinum core-shell catalyst, $\mathrm{Pt}_{1} \mathrm{Ag}_{1} @ \mathrm{Pt}_{1} / \mathrm{f}-\mathrm{CNC}$ in our study. Figure 9 compares methanol oxidation voltammetry for these nanoparticle materials. Both nanoparticles have efficient electrooxidative properties towards methanol in acidic electrolyte. The core-shell platinum-silver nanomaterial with its platinum surface is an impervious particle and therefore would be expected to display electrocatalytic behaviour similar to that of a mono-metallic platinum nanoparticle of identical size. The electro-etching process is crucial to the modification of the catalytic property of platinum- 


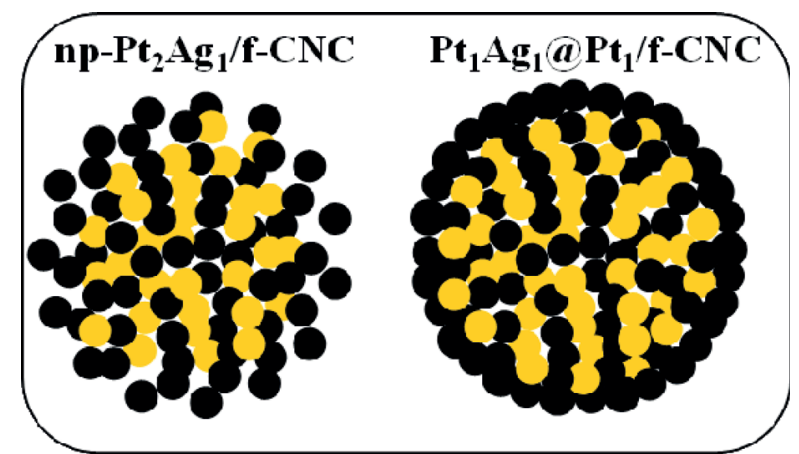

Fig. 8. Graphical representation for $n p-\mathrm{Pt}_{2} \mathrm{Ag}_{1} / \mathrm{f}-\mathrm{CNC}$ and $\mathrm{Pt}_{1} \mathrm{Ag}_{1} @ \mathrm{Pt}_{1} / \mathrm{f}-\mathrm{CNC}$. Pt and $\mathrm{Ag}$ are indicated by black and yellow spheres respectively; CNC not shown.

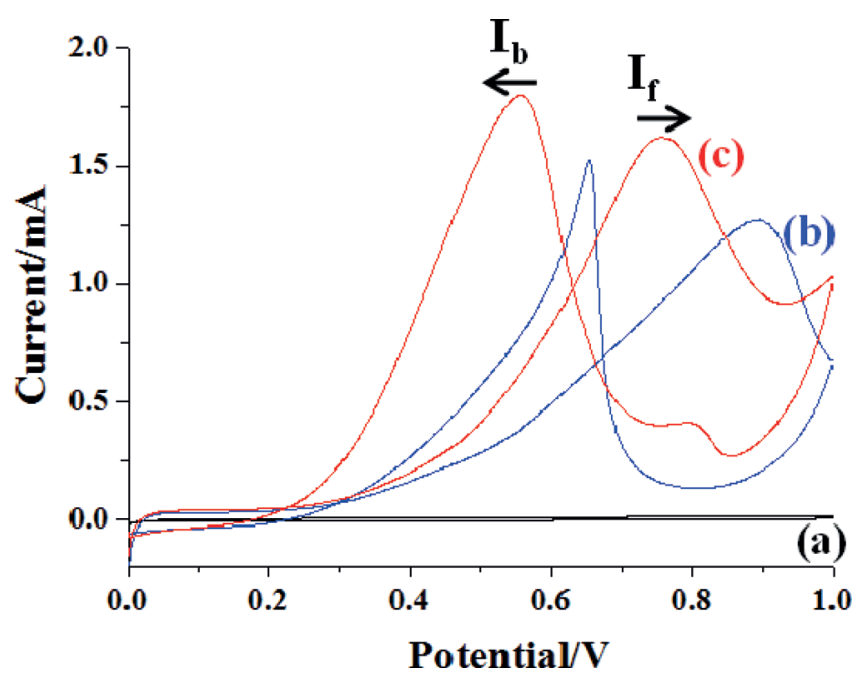

Fig. 9. Cyclic voltammetry (first scan) of methanol in sulfuric acid solution at: (a) $\mathrm{CNC}$, (b) $\mathrm{Pt}_{1} \mathrm{Ag}_{1} @ \mathrm{Pt}_{1} / \mathrm{f}-\mathrm{CNC}$ and (c) $n p$ $\mathrm{Pt}_{2} \mathrm{Ag}_{1} / \mathrm{f}-\mathrm{CNC}$ modified glassy carbon electrode. Electrolyte: $1.0 \mathrm{M} \mathrm{CH}_{3} \mathrm{OH}$ in $0.5 \mathrm{M} \mathrm{H}_{2} \mathrm{SO}_{4}$. Electrode potentials vs. $\mathrm{Ag} / \mathrm{AgCl}$, with a scan rate $0.05 \mathrm{~V} / \mathrm{s}$. Note; $\mathrm{Pt}_{1} \mathrm{Ag}_{1} @ \mathrm{Pt}_{1} / \mathrm{f}-\mathrm{CNC}$ underwent the same electro-etch as $n p-\mathrm{Pt}_{2} \mathrm{Ag}_{1} / \mathrm{f}-\mathrm{CNC}$.

silver nanomaterials by altering surface structure, thereby altering the nature of the nanocatalyst's interaction with methanol molecules. Methanol electrooxidation data bears this out. Oxidation potentials for the methanol reaction at the platinum shell particle $\left(\mathrm{Pt}_{1} \mathrm{Ag}_{1} @ \mathrm{Pt}_{1} / \mathrm{f}-\mathrm{CNC}\right)$ are more anodic, e.g. $+895 \mathrm{mV}$ with respect to $+759 \mathrm{mV}$ for the porous core-shell catalyst $\left(n p-\mathrm{Pt}_{2} \mathrm{Ag}_{1} / \mathrm{f}-\mathrm{CNC}\right)$.

Current ratios measured from voltammetry data for the porous nanomaterial $\left(n p-\mathrm{Pt}_{2} \mathrm{Ag}_{1} / \mathrm{f}-\mathrm{CNC}\right)$ were of the order of 0.86 (first scan data), while those derived for the core-shell particle, $\mathrm{Pt}_{1} \mathrm{Ag}_{1} @ \mathrm{Pt}_{1} / \mathrm{f}-\mathrm{CNC}$, were consistently under 0.80. A relevant commercial comparison for methanol electrooxidation is the $\mathrm{Pt} / \mathrm{C}$ catalyst developed by Johnson Matthey, where $I_{\mathrm{f}} / I_{\mathrm{b}}$ ratios are reported at around 0.77 [34]. This electrochemical data is indicative of a higher methanol oxidation efficiency and therefore greater potential catalytic utility of the porous core-shell platinum-silver nanomaterial reviewed in this study. The improved performance is due to the porous surface structure of the material with contributions from the alloyed core via an electronic effect. The electronic structure of $\mathrm{Pt}$ atoms modified by $\mathrm{Ag}$ in the core of the particle could weaken the $\mathrm{Pt}-\mathrm{CO}$ interaction thereby reducing $\mathrm{CO}$ poisoning effects.

Current density measurements for methanol electrooxidation were of the order of $135 \mathrm{~mA} \mathrm{mg}^{-1}$ for the porous nanoparticle $\left(n p-\mathrm{Pt}_{2} \mathrm{Ag}_{1} / \mathrm{f}-\mathrm{CNC}\right)$ compared to $97.6 \mathrm{~mA} \mathrm{mg}^{-1}$ for the $\mathrm{Pt}_{1} \mathrm{Ag}_{1} @ \mathrm{Pt}_{1} / \mathrm{f}-\mathrm{CNC}$. Therefore the porous nanocatalyst's rate of oxidation of methanol molecules per $\mathrm{mg} \mathrm{Pt}$ is greater than its platinum-shell counterpart, i.e. an efficiency gain of $38 \%$. The utility of the porous nanocatalyst is also evident in repeat-scan measurements. Here, the $n p-\mathrm{Pt}_{2} \mathrm{Ag}_{1} / \mathrm{f}-\mathrm{CNC}$ material showed a decrease in methanol oxidation current of $3.6 \%$ over a sequence of 30 consecutive scans, while the drop in oxidation efficiency for the $\mathrm{Pt}_{1} \mathrm{Ag}_{1} @ \mathrm{Pt}_{1} / \mathrm{f}-\mathrm{CNC}$ catalyst was more extreme with a $33.6 \%$ decrease. The improved performance observed here is due largely to the porous morphology of $n p-\mathrm{Pt}_{2} \mathrm{Ag}_{1} / \mathrm{f}-\mathrm{CNC}$. Its larger surface area and availability of active sites results in high Pt site utilisation and improved electrocatalytic activity towards methanol.

\section{Conclusions}

A novel type of nanocatalyst for use in methanol electrooxidation reactions was synthesised and characterised. The catalyst is composed of nanoparticle alloy of platinum and sliver supported on a carbon nanochips platform. The platinum-silver particle was electro-etched in acidic electrolyte to remove silver atoms from the surface, a process which gave rise to a platinum-silver nanoparticle possessing a porous platinum shell and a platinumsilver alloy core. The porous platinum-silver nanoparticle was then investigated with respect to methanol electrooxidation. The nanomaterial has improved resistive characteristics towards carbon monoxide poisoning and provides higher current densities per mass of platinum relative to similar platinum-shell catalysts. Further work on $n p$ $\mathrm{Pt}_{2} \mathrm{Ag}_{1} / \mathrm{f}-\mathrm{CNC}$ nanomaterials will involve testing for methanol fuel-cell (DMFC) applications.

\section{Note: Synthesis of $\mathbf{P t}_{\mathbf{1}} \mathbf{A g}_{\mathbf{1}} @ \mathbf{P t}_{\mathbf{1}} / \mathbf{f}-\mathbf{C N C}$}

The $\mathrm{Pt}_{1} \mathrm{Ag}_{1} @ \mathrm{Pt}_{1} / \mathrm{f}-\mathrm{CNC}$ (total metal loading, 20wt\%) catalyst was synthesised via a two-step procedure. Firstly, carbon nanochips supported $\mathrm{Pt}_{1} \mathrm{Ag}_{1}$ alloy catalyst $\left(\mathrm{Pt}_{1} \mathrm{Ag}_{1} /\right.$ $\mathrm{f}-\mathrm{CNC}$ ) was prepared in a similar way as explained for $\mathrm{Pt}_{2} \mathrm{Ag}_{1} / \mathrm{f}-\mathrm{CNC}$ (Section 2.3) with the exception that half $(6.67 \%, 10.23 \mathrm{mg})$ of the total $\mathrm{Pt}(13.33 \%, 20.45 \mathrm{mg})$ was used in the first step and the $\mathrm{Pt}: \mathrm{Ag}$ ratio was maintained at $1: 1$ on carbon nanochips instead of $2: 1$ (in the case of $\mathrm{Pt}_{2} \mathrm{Ag}_{1} / \mathrm{f}-\mathrm{CNC}$ (20\%), Section 2.3). The total metal loading in the first step was $13.33 \%$ (Pt:Ag, 1:1, 6.67\% each), and synthesised catalyst was labelled as $\mathrm{Pt}_{1} \mathrm{Ag}_{1} / \mathrm{f}-$ CNC. 
$\mathrm{Pt}_{1} \mathrm{Ag}_{1} / \mathrm{f}-\mathrm{CNC}$ was then processed for the second step to make a $\mathrm{Pt}$ shell (another portion of $\mathrm{Pt} 6.67 \%$, $10.23 \mathrm{mg}$ ) surrounding the $\mathrm{Pt}_{1} \mathrm{Ag}_{1}$ nanoparticles core $\left(\mathrm{Pt}_{1} \mathrm{Ag}_{1} / \mathrm{f}-\mathrm{CNC}\right.$, prepared in first step), by maintaining the same overall metallic loading as for $\mathrm{Pt}_{2} \mathrm{Ag}_{1} / \mathrm{f}-\mathrm{CNC}(\mathrm{Pt}+$ $\mathrm{Ag}=20 \%$, Section 2.3). For Pt shell formation, the same procedure under similar conditions (ethylene glycol/ water, $3: 2$ ) was repeated and $60 \mathrm{mg}$ of sodium citrate was used in the first step and $30 \mathrm{mg}$ in second step. The so-obtained nanocatalyst was labelled as $\mathrm{Pt}_{1} \mathrm{Ag}_{1} @ \mathrm{Pt}_{1} / \mathrm{f}-\mathrm{CNC}$. From the TGA analysis, the total metallic content $(\mathrm{Pt}+$ $\mathrm{Ag}$, wt $\%)$ for $\mathrm{Pt}_{1} \mathrm{Ag}_{1} @ \mathrm{Pt}_{1} / \mathrm{f}-\mathrm{CNC}$ was quantified at $23.9 \%$.

\section{Acknowledgements}

Dr Baljit Singh acknowledges Technological Sector Research Strand III, Research and Development Programme for funding.

\section{References}

[1] http://www.viaspace.com

[2] R. Bashyam, P. Zelenay, Nature 2006, 443, 63-66.

[3] C. Wang, H. Daimon, S. Sun, Nano Lett. 2009, 9, $1493-$ 1496.

[4] Z. Peng, H. Yang, Nano Today 2009, 4, 143-164.

[5] Y. Cheng, S. P. Jiang, Electrochim. Acta 2013, 99, 124-132.

[6] C-T. Hsieh, J.-Y. Lin, S.-Y. Yang, Physica E: Low-dim. Syst. Nanostruct. 2009, 41, 373-378.

[7] S. Basri, S. K. Kamarudin, W. R.W. Daud, Z. Yaakub, Int. J. Hydrogen Energy 2010, 35, 7957-7970.

[8] J. N. Tiwari, R. N. Tiwari, G. Singh, K. S. Kim, Nano Energy 2013, 2, 553-578.

[9] Y. Shao-Horn, W. C. Sheng, S. Chen, P. J. Ferreira, E. F. Holby, D. Morgan, Topics Catalysis 2007, 46, 285-305.

[10] B. Li, D. C. Higgins, S. Zhu, H. Li, H. Wang, J. Ma, Z. Chen, Catal. Commun. 2012, 18, 51-54

[11] S. Sun, G. Zhang, D. Geng, Y. Chen, M. N. Banis, R. Li, M. Cai, X. Sun, Chem. Eur. J. 2010, 16, 829-835.

[12] O. Guillen-Villafuerte, R. Guil-Lopez, E. Nieto, G. García, J. L. Rodríguez, E. Pastor, J. L. G. Fierro, Int. J. Hydrogen Energy 2012, 37, 7171-7179.
[13] X. Zhang, D. Li, D. Dong, H. Wang, P. A. Webley, Mater. Lett. 2010, 64, 1169-1172.

[14] C. Cui, L. Gan, M. Heggen, S. Rudi, P. Strasser, Nat. Mater. 2013, 12, 765-771.

[15] S. S. Kim, C. Kim, H. Lee, Top. Catal. 2010, 53, 686-693.

[16] M. V. Martínez-Huerta, S. Rojas, J. L. Gomez de la Fuente, P. Terreros, M. A. Pena, J. L. G. Fierro, Appl. Catal. B 2006, $69,75-84$.

[17] N. Kristian and X. Wang, Electrochem. Commun. 2008, 10, $12-15$.

[18] K. Shimizu, I. Francis Cheng, C. M. Wai, Electrochem. Commun. 2009, 11, 691-694.

[19] H. Zhao, L. Li, J. Yang, Y. Zhang, Electrochem. Commun. 2008, 10, 1527-1529.

[20] J. Dai, P. Yao, N. Hua, P. Yang, Y. Du, J. Dispersion Sci. Technol. 2007, 28, 872-875.

[21] A. Selim, U. N. Anand, M. Manos, E. Bryan, Nature Mater. 2008, 7, 333-338.

[22] J. Wang, K. P. Loh, Y. L. Zhong, M. Lin, J. Ding, Y. L. Foo, Chem. Mater. 2007, 19, 2566-2572.

[23] J. Zeng, J. Yang, J. Y. Lee, W. Zhou, J. Phys. Chem. B 2006, $110,24606-24611$.

[24] J. Erlebacher, M. J. Aziz, A. Karma, N. Dimitrov, K. Sieradzki, Nature 2001, 410, 450-453.

[25] Z. Qi, C. Zhao, X. Wang, J. Lin, W. Shao, Z. Zhang, X. Bian, J. Phys. Chem. C 2009, 113, 6694-6698.

[26] X. Wang, W. Wang, Z. Qi, C. Zhao, H. Ji, Z. Zhang, Int. J. Hydrogen Energy 2012, 37, 2579-2587.

[27] C. Zhang, J. Sun, J. Xu, X. Wang, H. Ji, C. Zhao, Z. Zhang, Electrochim. Acta 2012, 63, 302-311.

[28] Z. Qi, H. Geng, X. Wang, C. Zhao, H. Ji, C. Zhang, J. Xu, Z. Zhang, J. Power Sources 2011, 196, 5823-5828.

[29] Z. Zhang, Y. Wang, X. Wang, Nanoscale 2011, 3, 16631674.

[30] X. Xu, R. T. K. Baker, U.S. Patent, 7550611 (US7550611 B2), 2009.

[31] L. Liu, E. Pippel, R. Scholz, U. Gosele, Nano Lett. 2009, 9, $4352-4358$.

[32] B. Singh, L. Murad, F. Laffir, C. Dickinson, E. Dempsey, Nanoscale 2011, 3, 3334-3349.

[33] B. Singh, E. Dempsey, RSC Adv. 2013, 3, 2279-2287.

[34] X. Ge, R. Wang, P. Liu, Y. Ding, Chem. Mater. 2007, 19, 5827-5829.

Received: August 11, 2014

Accepted: October 1, 2014 Published online: November 14, 2014 